\title{
INSTITUCIONALIZAÇÃO DE COMPRAS PÚBLICAS SUSTENTÁVEIS: UMA ANÁLISE DA EXPERIÊNCIA DO GOVERNO DE MINAS GERAIS ${ }^{1}$
}

\author{
Ricardo Almeida Marques Mendonça ${ }^{2}$ \\ Marcus Vinicius Gonçalves da $\mathrm{Cruz}^{3}$ \\ Armindo dos Santos de Sousa Teodosio ${ }^{4}$ \\ Luciana Sardinha Pinto Raso ${ }^{5}$
}

http://dx.doi.org/10.1590/1413-2311.161.61307

\begin{abstract}
RESUMO
$\mathrm{O}$ artigo tem por objetivo analisar, sob a perspectiva da teoria institucional, o processo de implantação de compras públicas sustentáveis pelo Governo do Estado de Minas Gerais, um dos pioneiros nesse processo no Brasil. Realizou-se pesquisa qualitativa por meio de estudo de caso único, utilizando-se de análise documental e entrevistas semi-estruturadas. Pôde-se compreender o papel de diferentes atores que se caracterizaram como forças institucionais no campo organizacional da difusão de compras públicas sustentáveis. A análise demonstra a preponderância de mecanismos de natureza coercitiva, além de circunstâncias ligadas aos "mitos e cerimônias" na difusão de compras públicas sustentáveis no governo em Minas Gerais.
\end{abstract}

Palavras-Chave: Compras Públicas. Sustentabilidade. Gestão Pública. Institucionalismo.

\section{INSTITUTIONALIZATION OF SUSTAINABLE PROCUREMENT IN GOVERNMENT:}

\section{AN ANALYSIS OF THE EXPERIENCE OF THE MINAS GERAIS GOVERNMENT}

\begin{abstract}
The article aims to analyze the institutionalization of sustainable public procurement by the government of Minas Gerais, one of the pioneers in this process in Brazil. We conducted qualitative research through single case study, using document analysis and semi-structured interviews. You might understand the role of different actors who were characterized as institutional forces in the organizational field of dissemination of sustainable public procurement. The analysis shows the preponderance of coercive nature mechanisms, and circumstances related to "myths and ceremonies" in the dissemination of sustainable public
\end{abstract}

\footnotetext{
${ }^{1}$ Recebido em 02/01/2016; aprovado em 18/07/2017.

${ }^{2}$ Fundação João Pinheiro - ricardoamm@ yahoo.com.br.

${ }^{3}$ Fundação João Pinheiro - ricardoamm@yahoo.com.br.

${ }^{4}$ PUC-Minas - armindo.teodosio@gmail.com.

${ }^{5}$ Fundação João Pinheiro - luciana_moraes_r@ @otmail.com.
} 
procurement in government in Minas Gerais.

Key-Words: Public Procurement. Sustainability. Public Management. Institutionalism.

\title{
INSTITUCIONALIZACIÓN DE LA CONTRATAÇÃO PÚBLICA SOSTENIBLE: UN ANÁLISIS DE LA EXPERIENCIA DEL GOBIERNO DE MINAS GERAIS
}

\begin{abstract}
RESUMEN
El artículo tiene como objetivo analizar la institucionalización de las compras públicas sostenibles por el gobierno de Minas Gerais, uno de los pioneros en este proceso en Brasil. Hemos llevado a cabo la investigación cualitativa a través del estudio solo caso, utilizando el análisis de documentos y entrevistas semi-estructuradas. Es posible entender el papel de los diferentes actores que se caracterizaron como fuerzas institucionales en el campo de la organización de la difusión de la contratación pública sostenible. El análisis muestra la preponderancia de mecanismos coercitivos naturaleza y circunstancias relacionadas con "mitos y ceremonias" en la difusión de las compras públicas sostenibles en el gobierno de Minas Gerais.
\end{abstract}

Palabras-clave: Contratación Pública. Sostenibilidad. Gestión Pública. Institucionalismo.

\section{INTRODUÇÃO}

O presente artigo tem como objetivo analisar, sob a perspectiva da teoria institucional, o processo de implantação de compras públicas sustentáveis pelo Governo do Estado de Minas Gerais, identificando as principais evidências da institucionalização desta prática. Esse processo insere-se no contexto geral das questões relacionadas com a sustentabilidade que vêm ganhando força nas últimas décadas (BARBIERI, 2009; GROB; BENN, 2014; OLIVEIRA; SANTOS, 2015).

As preocupações com as questões ambientais se deslocaram da posição periférica, que até então ocupavam, e adquiriram centralidade, face ao diagnóstico de uma crise ambiental sem precedentes (RIBEIRO, 2009). Silva Júnior et al. (2009) afirmam que, se antes as declarações de um iminente perigo de desastre ambiental partiam apenas de ambientalistas e cientistas, hoje também partem de economistas e líderes mundiais, que até pouco tempo tratavam o tema de forma secundária, senão de modo indiferente.

Para Andrade e Costa (2008), é a primeira vez na história contemporânea que uma questão não relacionada com os clássicos problemas de economia ou segurança ocupa um lugar de destaque na agenda dos principais países do mundo. Deste modo, o debate acerca do desenvolvimento sustentável tem, cada vez mais, ocupado a agenda política de diversos 
governos, sejam nacionais ou subnacionais, envolvendo ainda o mercado e a sociedade civil. Segundo Abramovay (2010), vive-se agora em um mundo no qual os temas ambientais se tornam cada vez mais preocupações centrais em todos os níveis de tomada de decisão, tanto nas organizações (ALPERSTEEDT et al., 2010; GROB; BENN, 2014), como governos (OLIVEIRA; SANTOS, 2015; COUTO; COELHO, 2015).

Silva Júnior et al. (2009) afirmam que, ao longo das últimas décadas, o enfoque da gestão ambiental tem sofrido transformações, com o surgimento de novos instrumentos e envolvimento de múltiplos agentes, tanto na esfera pública quanto no âmbito privado, na busca de soluções mais eficazes para os impactos ambientais negativos gerados pelos processos de desenvolvimento. Neste contexto, afirma Barbieri (2009), o Estado assume um importante papel de agente de regulação ambiental, sendo, inclusive, no caso do Brasil, uma obrigação imposta pela própria Constituição Federal, na qual os entes federativos passam a atuar, como atestam Ensslin et al. (2015).

Dentre os diversos instrumentos de gestão ambiental à disposição do Poder Público, uma seara que vem ganhando importância em tempos recentes, refere-se às compras públicas sustentáveis que, dado o poder de compras do aparelho de Estado no Brasil, estimado em torno de $10 \%$ a $15 \%$ do PIB em 2014, segundo dados do Ministério do Planejamento do Governo Federal (BRASIL, 2015), teria o condão de alterar a cadeia produtiva criando, assim, um novo mercado com produtos e serviços sustentáveis. Por outro lado, no mundo inteiro, existe um debate sobre a legalidade da opção mais sustentável em termos socioambientais nas licitações públicas. Isto porque, via de regra, os produtos sustentáveis geralmente possuem um preço superior se comparados aos produtos similares tradicionais (BIDERMAN et al., 2008).

No caso brasileiro, o ordenamento jurídico vem se adaptando para a realização de licitação sustentável, pois, se por um lado consagra o princípio da economicidade, por meio da determinação da escolha da proposta mais vantajosa para a administração, por outro lado determina a promoção do desenvolvimento sustentável. Assim, comandos normativos devem compatibilizar-se para a realização das compras públicas sustentáveis (COUTO; COELHO, 2015).

Verifica-se no contexto brasileiro que o estado de Minas Gerais, o estado de São Paulo e o município de São Paulo foram os pioneiros na implantação de uma política de compras públicas sustentáveis, por meio do projeto "Fomentando as Compras Públicas Sustentáveis no Brasil". O que se percebia, até então, eram ações isoladas de diversos governos subnacionais em prol das aquisições de produtos sustentáveis (COUTO; COELHO, 2015), mas não como 
uma política pública estruturada.

O presente estudo optou pela análise do caso de Minas Gerais pelo fato de ser o ente federativo que apresentava maiores evidências de avanços na implantação de uma política de compras públicas sustentáveis. Buscou-se analisar, sob a perspectiva da teoria institucional, o processo de implantação de compras públicas sustentáveis pelo Governo do Estado de Minas Gerais

Percebe-se que a literatura sobre compras públicas sustentáveis ainda é muito incipiente no Brasil, de modo que o presente trabalho busca avançar nessa discussão no âmbito acadêmico e assim estimular estudos posteriores. Considera-se, ainda, a importância desta análise para que o Poder Público tenha subsídios, com fundamentação teórica e prática, para elaborar políticas públicas que aprimorem a preservação ambiental a partir das compras públicas.

A escolha da teoria institucional como suporte teórico relaciona-se à necessidade de legitimidade quando da introdução de novas práticas organizacionais, o que ocorre quando da inserção da política das compras públicas sustentáveis. Meyer e Rowan (1977) argumentam que as organizações que absorvem aspectos racionais socialmente legítimos na sua estrutura formal aumentam a sua legitimidade e capacidade de sobrevivência. A ideia de sustentabilidade no ambiente geral requer a introdução de práticas a serem legitimadas e posteriormente difundidas em termos de similaridade, no que ficou estabelecido como isomorfismo (GROB; BENN, 2014). A identificação das forças institucionais, nos termos de Scott (2008), e as evidências dos mecanismos de isomorfismo são partes integrantes da análise realizada neste artigo sobre as compras públicas sustentáveis.

\section{ABORDAGEM INSTITUCIONAL}

A abordagem do institucionalismo nos estudos organizacionais é uma tentativa de se contrapor ao modelo racionalista, que teve como foco as exigências técnicas dos processos gerenciais e produtivos. Ao contrário, a teoria institucional examina elementos de redes relacionais e de sistemas culturais que modelam e sustentam as estruturas e a ação das organizações, como preconizado por Selznick (1996).

Meyer e Rowan (1977) afirmam que, nas sociedades modernas, as estruturas formais das organizações são estabelecidas em contextos altamente institucionalizados, onde estas estruturas refletem os entendimentos difundidos na realidade social. Muitas dessas posições, políticas, programas e procedimentos das organizações modernas decorrem dos mitos criados 
pela opinião pública, opinião de cidadãos destacados, conhecimento legitimado pelo sistema, prestígio social, leis e definições de negligência e prudência decididas pelos tribunais. Deste modo, na medida em que as redes de relacionamentos nas sociedades pós-industriais se tornam densas e complexas, surge um número cada vez maior de mitos racionalizados.

Ainda, Meyer e Rowan (1977) afirmam que determinados formatos organizacionais se perpetuam ao se converterem em regras institucionalizadas. Ao delinear uma estrutura formal que adere a prescrições dos mitos no ambiente institucional, uma organização demonstra que atua com base em valores coletivamente aceitos, de maneira adequada. Neste termo, o êxito organizacional depende de outros fatores que não somente a coordenação e o controle eficiente das atividades produtivas. Independente de sua eficiência produtiva, as organizações que existem em ambientes institucionais complexos e têm êxito na realização de práticas isomórficas nestes ambientes, obtêm a legitimidade dos recursos que requerem para sobreviver (MEYER; ROWAN, 1977). Assim, Machado-da-Silva e Fonseca (1993) acrescentam que a conformidade aos valores e normas sociais, ou a legitimidade, mais até que o próprio desempenho, é que determina a sobrevivência das organizações.

De acordo com Meyer e Rowan (1977), diante de incertezas ambientais, a competição entre as organizações volta-se tanto para a busca de recursos e consumidores, assim como de legitimidade institucional, fazendo com que as práticas organizacionais sejam cada vez mais homogêneas, isomórficas, resultando, assim, em menor variedade e instabilidade institucional. Em suma, sob o prisma do institucionalismo, as organizações tornam-se cada vez mais semelhantes a fim de se adequarem ao ambiente em que se inserem. Tal fenômeno é explicado por práticas isomórficas de natureza coercitiva, mimética e normativa.

O isomorfismo coercitivo, de acordo com DiMaggio e Powell (1991, p. 77) "resulta tanto de pressões formais quanto pressões informais exercidas sobre as organizações por outras organizações das quais elas dependem, e pelas experiências culturais da sociedade em que as organizações atuam”, podendo referidas pressões serem sentidas como coerção, persuasão, ou como convite para se unirem em conluio. Neste caso, as organizações se tornam cada vez mais homogêneas dentro de determinados domínios e cada vez mais organizadas em torno de rituais em conformidade com as instituições maiores.

Já o isomorfismo mimético provém de uma incerteza, que pode ser decorrente de tecnologias não compreendidas, metas ambíguas, incertezas simbólicas, que constitui uma força poderosa que encoraja a imitação. Os autores destacam as vantagens em termos de economia das ações humanas ao se adotar um comportamento mimético. Neste caso, as organizações tendem a tomar como modelo outras organizações que elas percebam ser mais 
legítimas ou bem-sucedidas.

Por seu turno, o isomorfismo normativo, outra fonte de mudanças organizacionais, decorre principalmente da profissionalização, assim entendido como o esforço coletivo para definir as condições e métodos de seus trabalhos. Neste caso, a profissionalização é importante fonte de isomorfismo, como forma de controlar a "produção de produtos", tendo como exemplo a educação formal, produzida cientificamente e a constituição e crescimento das redes profissionais.

Cabe aqui ressaltar que DiMaggio e Powell (1991) advertem que, apesar de ser esta uma tipologia analítica, os processos de isomorfismo não são tipos empiricamente distintos, podendo se misturar no contexto ambiental. Assim, as organizações, ao demonstrar que atuam de acordo com as normas coletivamente compartilhadas, podem ganhar reconhecimento externo e assegurar seu desenvolvimento, o que remete às premissas de Meyer e Rowan (1977).

Nos termos de Tolbert e Zucker (2007, p.203) o processo de institucionalização se inicia com uma inovação, passa pela habitualização e objetivação e termina com a sedimentação. Esse conjunto de processos sequenciais sugere uma variação nos níveis de institucionalização, implicando que "alguns padrões de comportamento social estão mais sujeitos do que outros à avaliação crítica, modificação e mesmo eliminação", dependendo de seu grau de profundidade no sistema social.

Observa Scott (2008) que as instituições são estruturas sociais duráveis, multifacetadas, feitas de elementos simbólicos, atividades sociais, e recursos materiais. Apresentam características próprias como relativa resistência à mudança, com tendência a serem transmitidas através de gerações, sendo mantida e reproduzida. Elas exibem estas propriedades em decorrência dos processos em movimento dos elementos regulativos, normativos e cognitivos sendo que estes elementos são centrais na construção da estrutura institucional, guiando o comportamento institucional e as resistências à mudança. Os três elementos formam um movimento contínuo do "consciente para o inconsciente, do legalmente imposto para o tido como certo" (HOFFMAN, 1997 apud SCOTT, 2008, p. 50). Assim, uma abordagem possível seria ver estes três elementos contribuindo com interdependência e se reforçando mutuamente para um poderoso quadro social.

$\mathrm{O}$ aspecto regulativo, de acordo com Scott (2008, p. 52), pelo qual as "instituições compelem e regularizam comportamentos", se dá, principalmente, por meio de três processos: fixação de regras, monitoramento e sanções. Nesta concepção, o processo regulatório envolve a capacidade de estabelecer regras, inspecionar sua conformidade as regras estabelecidas e, 
quando necessário, aplicação de prêmios ou penalidades, de modo a influenciar, guiar, um comportamento futuro.

O pilar normativo é visto como impositivo de restrições no comportamento social que, ao mesmo tempo, autoriza e permite ação social. Conferem direito e responsabilidades, privilégios e obrigações, licenças e mandatos. Scott (2008) afirma que as instituições que se apoiam neste pilar têm como base as regras que são introduzidas pelas dimensões prescritivas, avaliativas, e de obrigatoriedade da vida social. O sistema normativo inclui valores e normas. Entende-se como valores, a concepção daquilo que é preferível ou desejável. Por seu turno, normas descrevem e especificam como as coisas devem ser feitas, definindo legitimidades. Juntos, valores e normas, constroem bases em que as estruturas ou comportamentos existentes podem ser comparados ou avaliados.

Já no pilar cognitivo, a atenção é direcionada para os aspectos simbólicos das ações, resultantes das interpretações e representações dos indivíduos em relação ao ambiente em que se inserem, constituído por regras, crenças, valores e redes relacionais. Assim, a sobrevivência de uma organização não se restringe a capacidade adaptativa a especificações técnicas e financeiras, mas também a fatores de apoio e legitimidade. Os atores que se alinham com as crenças culturais dominantes se sentem inseridos e conectados, enquanto aqueles desconectados são considerados sem noção ou loucos (SCOTT, 2008).

Scott (2008) atenta que, embora o poder seja importante para suportar a legitimidade da instituição, não pode ser considerado o único fator. Além do poder, podem ser extraídos, dos três pilares anteriormente descritos, as seguintes bases de legitimidade inter-relacionadas: no pilar regulatório, a ênfase na conformidade com as regras; no pilar normativo, a ênfase na profunda base moral; e, por fim, no pilar cognitivo-cultural, a ênfase da legitimidade vem da conformidade de uma definição comum da situação, quadro, referência, ou estrutura modelo. O pilar cognitivo é o mais "profundo" nível porque baseia-se em significados pré-conscientes, tidos como certos. Segundo Scott (2008), o que é tomado como evidência de legitimidade varia de acordo com os elementos que a instituição privilegia, assim como quais audiências e autoridades são consultadas. Todavia, nas formas institucionais empiricamente analisadas, não se observa somente um único elemento presente, mas uma combinação destes elementos.

Scott (2008) ressalta a importância da identificação de forças que pressionam a institucionalização de determinados processos, podendo ser constituídas por grupos de interesse, parceiros estratégicos, entre outros. A ação de tais forças pode ser fundamental na promoção de mudanças nas organizações, nomeadas por Tolber e Zucker (2007), de inovação, habitualmente derivadas da necessidade de novos parâmetros tecnológicos, legais ou por força 
do mercado, fazendo com que o sistema vigente entre em crise, exigindo um novo patamar para o início do processo de institucionalização.

Por fim, Gorb e Benn (2015) evidenciam que a adoção de compras sustentáveis poderia ser explicada por meio da identificação de formas de isomorfismo. A pressão da legislação impulsiona a adoção de parâmetros na cadeia de suprimentos para atendimento a

licitações sustentáveis, ilustrando o isomorfismo coercitivo. Por sua vez, programas e políticas governamentais de compras sustentáveis levariam à disseminação de suas práticas por outras organizações estimulando um comportamento mimético entre os fornecedores e outras organizações que quisessem se inserir em programas e alianças voltadas para a sustentabilidade, pois com isso aumentariam as oportunidades de venda, inclusive ao aparelho de Estado. Ainda para os autores, os preceitos de sustentabilidade estão sendo difundidos no contexto educacional e de redes profissionais como as de auditores e contadores, responsáveis por averiguar os procedimentos legais, o que pode gerar práticas de isomorfismo normativo, para além daquelas provocadas pela força da obrigação social evidenciada por Scott (1995), ligada ao moral e ética, em termos de responsabilidade ambiental e de sustentabilidade, inclusive pelas organizações brasileiras, como destacam Mapurunga et al. (2015).

\section{DESENVOLVIMENTO SUSTENTÁVEL}

A década de 1970 e início da década de 1980 foram marcadas pelos primeiros passos em prol da consciência dos problemas ambientais no planeta Terra, em decorrência do crescimento industrial quantitativo descontrolado que vinha ocorrendo (OECD, 2000). Essa transformação de mentalidade fez surgir uma gestão ambiental "passiva", segundo a qual o Estado age emitindo comandos e realizando controle sobre a atividade produtiva, de modo a promover o controle da poluição (SILVA JÚNIOR et al., 2009). Nesta fase, há a prevalência de práticas chamadas "fim de tubo" (end-of-pipe), nas quais é instalado um coletor de emissão de materiais poluentes ao final do processo produtivo. Tais métodos têm natureza apenas corretiva, sem qualquer efeito de eficiência econômica no processo produtivo (BARBIERI, 2009).

Em um segundo momento, em decorrência da proliferação de graves acidentes ambientais ocorridos ao redor do mundo, principalmente na década de 1980, o Poder Público passou a agir de modo a prevenir a ocorrência de desastres ambientais, também mediante a adoção de comandos e controles. Nesta fase, há a determinação do Poder Público para que as empresas efetuassem troca de equipamentos, materiais e recursos energéticos, de modo a se 
alcançar uma produção mais eficiente e com menos riscos ao meio ambiente (SILVA JÚNIOR et al., 2009). Cumpre ressaltar que o modelo de desenvolvimento econômico dominante nas economias capitalistas ocidentais, baseava-se em ganhos crescentes de escala, por meio do uso intensivo e predatório de insumos produtivos, principalmente os de extração direta do meio ambiente.

A partir da década de 1990, mais precisamente após a realização da Rio-92 e a publicação da Agenda 21, a gestão ambiental passa para uma fase proativa, em que há o entendimento por parte de países e empresas de que as questões ambientais devem estar integradas ao todo, e não somente ligadas à produção. Sobre esta fase, Silva Júnior et al. (2009) afirmam que as empresas se tornaram uma das principais forças condutoras da sociedade em todos os níveis de abrangência, do global ao interior dos lares, dos acordos multilaterais às decisões corriqueiras do dia-a-dia de bilhões de pessoas em todas as partes do mundo. Daí a emergência de uma nova concepção de responsabilidade social corporativa que rejeita a velha fórmula que se satisfazia em produzir bens e serviços dentro da lei. A gestão ambiental deve fazer parte dessa nova responsabilidade social e, como tal, deve refletir o poder ampliado das empresas de modo que elas possam, de fato, tornarem-se parceiras do desenvolvimento sustentável, como nas iniciativas citadas por Mapuranga et al. (2015).

Nesta fase, os problemas ambientais são tratados como uma questão estratégica nas firmas envolvendo todas as áreas funcionais da estrutura empresarial. Além das clássicas práticas de controle e prevenção da poluição, as empresas passam a atuar com as perspectivas de redução de custos de produção. Por meio de uma produção mais limpa, as empresas procuram oportunidades mercadológicas em decorrência da crescente conscientização ambiental (BARBIERI, 2009). Advertem Gonçalves-Dias; Teodósio e Barbieri (2007), todavia, que esta evolução das ações ambientais na gestão empresarial, apesar de generalizada, não é uniforme. Isto porque, o local onde a atividade é exercida, o tipo de organização, o mercado fornecedor, o mercado consumidor, dentre outros, são essenciais na definição das estratégias empresariais em questões ambientais.

Nestes termos, vigora cada vez mais a possibilidade de estabelecer uma relação de soma positiva entre as atividades empresariais e o meio ambiente (ABRAMOVAY, 2010). Ainda assim, questões de natureza ambiental têm exigido participação vigorosa do Estado regulador. É o que se observa em todos os países em que o desenvolvimento sustentável tem tido êxito. Barbieri (2004) afirma, entretanto, que a participação vigorosa do Estado na gestão ambiental não é, por si só, garantia de que as questões ambientais serão tratadas corretamente pela comunidade e pelos agentes privados. A eficácia de uma política pública ambiental 
dependerá do grau de importância que a sociedade atribui às questões ambientais. Neste contexto, o Poder Público dispõe de uma série de instrumentos para a execução de sua gestão ambiental: instrumentos de conscientização social, instrumentos de comando e controle; e instrumentos econômicos.

Os instrumentos de conscientização social no campo da gestão ambiental pública incluem a educação ambiental, a propaganda mediante campanhas de divulgação, a disponibilização de acesso público às informações, os programas de certificação, entre outros. Como exemplo, Costa e Teodósio (2011) citam a possibilidade de formulação de políticas públicas para prestar informação e desenvolver a consciência da população em prol de um consumo sustentável, que minimizem os impactos ambientais e, ao mesmo tempo, atendam as necessidades básicas da sociedade.

Os instrumentos de comando e controle consistem na fixação de normas (comando) e em atividades de fiscalização (controle). São, portanto, regulamentações estabelecidas pelo Poder Público que fixam parâmetros técnicos para as atividades econômicas e que devem ser respeitadas pelos agentes econômicos sob pena de sanções. Suas principais modalidades são: licenças, zoneamento e padrões.

Já os instrumentos econômicos objetivam induzir o comportamento de pessoas e das organizações em relação ao meio ambiente por meio de medidas que representam benefícios ou ainda custos adicionais a elas. Estes mecanismos se concretizam mediante receitas e despesas públicas ou, ainda, criação de mercados artificiais (BARBIEIRI, 2004). Lima (2009) apresenta os principais tipos de instrumentos econômicos: taxas ambientais, criação de mercados, sistema de depósitos e reembolso, incentivos fiscais e subsídios, e poder de compra do aparelho de Estado. Algumas vantagens destes instrumentos econômicos de gestão ambiental pública em relação aos clássicos instrumentos de comando e controle, são a melhor eficácia com relação aos custos, incentivo permanente à redução da poluição, menor rigidez administrativa, e fonte de recursos ao Poder Público.

No campo dos instrumentos econômicos de gestão ambiental pública, há o poder de compra do aparelho de Estado que, dado seu potencial, por meio da inserção de critérios de sustentabilidade nas compras e contratações públicas, pode formar um mercado neste sentido (MENEGUZZI, 2011; SILVA; BARKI, 2012; COUTO; COELHO, 2015). Os valores desembolsados pelo aparelho de Estado por meio de contratações públicas são muito relevantes, uma vez que as compras governamentais - aí incluídos União, estados, Distrito Federal e municípios - representaram entre $10 \%$ e 15\% do Produto Interno Bruto brasileiro no ano de 2014 (BRASIL, 2015). Segundo Bliacheris (2011, p.144), “as licitações sustentáveis 
incorporam claros elementos de incentivo, ao abrir um mercado significativo às empresas que produzem de modo mais limpo e com menor impacto ambiental”. Assim, destacam Couto e Coelho (2015), o aparelho de Estado passaria a ter um papel indutor, ao criar mercado para tais produtos, possibilitando sua produção em uma escala maior, o que levaria à diminuição dos seus preços e facilitaria o seu acesso a um público mais amplo, como exemplificam Silva e Barki (2012).

\section{PROCEDIMENTOS METODOLÓGICOS}

O presente trabalho está fundamentado numa abordagem qualitativa e possui caráter descritivo. A escolha pela metodologia de pesquisa qualitativa se fez a partir do objetivo proposto, a saber: analisar, sob a perspectiva da teoria institucional, o processo de implantação de compras públicas sustentáveis pelo Governo do Estado de Minas Gerais. Neste caso, o método qualitativo mostra-se adequado, uma vez que este tipo de investigação prioriza a análise do "universo de significações, motivos, aspirações, atitudes, crenças e valores" (MINAYO, 1996, p.10). Utilizou-se o estudo de caso como estratégia de pesquisa, pois permite compreender o fenômeno estudado, preservando suas características

significativas, por focalizar nos "eventos da vida real", tais como: "os processos organizacionais e administrativos, ...”(YIN, 2010, p. 24).

Quanto aos procedimentos de coleta de dados, foram utilizadas as técnicas de pesquisa bibliográfica, análise documental, observação não-estruturada e entrevistas semi-estruturadas. Foram pesquisadas as normas, federal e estadual, pertinentes às compras públicas sustentáveis. A análise documental serviu para "reforçar o entendimento" da problemática, tendo em vista que os documentos "podem nos dizer muitas coisas sobre a maneira na qual os eventos são construídos, as justificativas empregadas". Além disso, "permitiria fazer comparações entre as interpretações dos eventos feitas" pelos participantes e "aquelas registradas nos documentos relacionados aos mesmos" (MAY, 2004, p. 205). As entrevistas semi-estruturadas foram realizadas com o auxílio de um roteiro de entrevista que, se por um lado, é composto por questões que foram prefixadas e que dizem respeito a uma temática específica; por outro, possui uma flexibilidade quanto à ordem, à necessidade de se fazer determinadas perguntas aos entrevistados e, ainda, conta com a possibilidade de se elaborar novas perguntas, sendo que essas decisões foram tomadas pelo entrevistador na própria situação de entrevista. A análise da política de compras sustentáveis foi efetuada até o final de 2014 tendo em vista a mudança de mandato governamental. Posteriormente, para elaboração 
do artigo, realizou-se uma atualização da pesquisa, que indicou sua vigência até o final de 2016.

Quanto ao critério de seleção dos entrevistados, privilegiou-se um conjunto de atores chave no processo de implantação das compras públicas sustentáveis no Governo do Estado de Minas Gerais, partindo do pressuposto de que estes possuem um "conjunto das experiências e expressões que se pretende objetivar com a pesquisa" (MINAYO, 1996, p. 102). Assim, optou-se pela técnica de amostragem não probabilística do tipo "Bola de Neve", levando em consideração a criteriosa seleção do ponto de partida para a coleta de dados ao escolher um entrevistado que ocupava um cargo estratégico, responsável por diversos processos de modernização da gestão no âmbito do Governo do Estado de Minas Gerais, quando do início da introdução dos critérios de sustentabilidade nas compras públicas realizadas pelo Governo. A opção por esta técnica justifica-se pelo fato de que a identificação da população alvo não é imediata, já que os atores chave poderiam não mais exercer atividades nos cargos que ocupavam inicialmente, podendo ser identificados pelo efeito bola de neve (BALDIN; MUNHOZ, 2011). No total, foram identificados sete atores chave do processo supracitado, sendo entrevistados seis destes; sendo todos eles servidores públicos do nível estratégico que lidavam com os processos decisórios envolvendo as compras no Governo do Estado de Minas Gerais. Para a manutenção do ético sigilo da fonte, os depoentes são denominados "Entrevistado A" até "Entrevistado F".

As entrevistas foram gravadas com a autorização dos entrevistados e, posteriormente, foi realizada uma análise sistemática de cada transcrição com um processo de categorização por meio de conteúdos predeterminados baseados na teoria institucional (CRESWELL, 2010). Deste modo, o conteúdo das entrevistas foi organizado por meio de um conjunto de temas ou categorias, como sugerido por Colbari (2014), assim constituído: forças institucionais; mitos e cerimônias; tipos de isomorfismo (coercitivo, normativo e mimético); e pilares de sustentação (regulador, normativo e cognitivo).

\section{IMPLANTAÇÃO DE COMPRAS SUSTENTÁVEIS NO GOVERNO DE MINAS GERAIS}

A partir de 2003, o Governo do Estado de Minas Gerais iniciou um projeto de modernização de sua administração pública em várias frentes de ação, sob a denominação de "Choque de Gestão", com o objetivo de melhorar a prestação de serviços públicos aos cidadãos, bem como equilibrar as contas públicas estaduais, então em notório déficit 
orçamentário, além de almejar gastar menos com o Governo e mais com o cidadão. Entre as diversas ações empreendidas no âmbito do programa, pode-se citar a redução de despesas com materiais e serviços, gerando grande economia, conforme indicam os estudos de Queiroz e Czagnazaroff (2010) e Brulon et al. (2013).

De acordo com os relatos dos entrevistados o processo de aprimoramento das compras públicas ganha impulso com a participação do Governo do Estado de Minas Gerais, a convite do ICLEI - Local Governments for Sustainability, em setembro de 2006, na cidade de Barcelona, na Espanha, da II Conferência Internacional sobre Compras Verdes, onde foram apresentadas as práticas mundiais mais avançadas sobre compras públicas sustentáveis. Posteriormente, em outubro de 2006, o ICLEI convidou formalmente o Governo do Estado de Minas Gerais a participar do projeto piloto denominado "Fomentando as Compras Públicas Sustentáveis no Brasil" que, tinha por objetivo, entre outros, canalizar toda capacidade de conhecimentos para promover as compras públicas sustentáveis, inicialmente em três governos escolhidos como pilotos no Brasil, em decorrência da importância política e volume de compras públicas realizadas: o do estado de Minas Gerais, o do estado de São Paulo e o do município de São Paulo. A parceria entre a administração mineira e o ICLEI para a implantação do projeto foi formalizada em fevereiro de 2007, para um período de vigência de maio de 2007 a março de 2009, momento em que o Governo do Estado de Minas Gerais passou a se tornar membro associado do ICLEI.

Os documentos consultados apontam que este projeto desenvolvido pelo ICLEI juntamente com os governos de Minas Gerais, do estado de São Paulo e do município de São Paulo, contou com o apoio técnico da Fundação Getúlio Vargas - FGV, por meio de seu Centro de Estudos em Sustentabilidade - GVces, tendo sido financiado pelo Ministério para Assuntos de Meio Ambiente, Alimentos e Rurais do Reino Unido - DEFRA. Segundo informou um dos entrevistados, o ICLEI já tinha uma parceria com o Reino Unido: "que já tinha um projeto muito avançado em compras verdes e que eles podiam estar nos apoiando, $e$ isto praticamente não tinha custo nenhum para o Estado à época, era quase que como uma prestação voluntária, porque era interessante para o ICLEI ter aderência de mais países e estados..." (Entrevistado F).

Conforme documento apresentado pelo ICLEI, um dos objetos do desenvolvimento deste projeto piloto nos referidos entes federativos foi influenciar os outros estados brasileiros e o Governo Federal para promoverem estas práticas em todo Brasil, fomentando a multiplicação e o desenvolvimento de uma estratégia de compras públicas sustentáveis no país. 
Entre as principais atividades previstas pelo projeto "Fomentando as Compras Públicas Sustentáveis no Brasil”, destacam-se: Pesquisa de critérios para compras públicas e indicadores; Mapeamento das práticas de compras e identificação das categorias a serem alcançadas pelo projeto; Desenvolvimento da metodologia de compras públicas sustentáveis e ferramentas específicas de treinamento; Cursos de capacitação de compras sustentáveis para servidores atuantes na área; Metodologia aplicada aos sistemas de compras, incluindo atualização dos sistemas de compras com produtos e critérios sustentáveis, integrados em editais de licitação; Divulgação das práticas de compras sustentáveis através de diferentes veículos de comunicação; Monitoramento e avaliação contínua; Seminários para construir conscientização para as compras sustentáveis; Divulgação dos resultados obtidos e compartilhamento de experiências. Em relação aos resultados esperados, poder-se-ia mencionar: Compromisso político e técnico dos governos para executar as práticas de compras públicas sustentáveis; Desenvolvimento de critérios e recomendações para práticas de compras públicas sustentáveis; Capacidade dos governos pilotos empreenderem práticas de compras sustentáveis; Reforço dos mercados locais e nacionais e atração dos fornecedores.

Conforme consta nos documentos consultados, a parceria do Governo do Estado de Minas Gerais com o ICLEI para a implantação do projeto foi celebrada no mesmo momento em que o Governo desenvolvia o projeto de "Gestão Estratégica de Suprimentos" - GES, o que levou a uma decisão de conciliar ambos os projetos. Deste modo, a adoção de práticas de aquisição e de consumo sustentável foi incluída dentro do projeto de "Gestão Estratégica de Suprimentos", observando-se o que se chamou de "tripé da sustentabilidade", no qual se destacam três premissas: (i) prosperidade econômica; (ii) responsabilidade social; e (iii) administração ambiental.

Deste modo, os produtos e serviços, para aquisição pelo Governo, foram separados em cinco 'famílias' eleitas para integrar uma primeira etapa do projeto GES, que avaliava tais produtos e serviços também sob o critério da sustentabilidade. Importante aqui mencionar, a realização de consultas públicas antes da publicação do edital de licitação contendo exigências de sustentabilidade ambiental, de modo a informar aos fornecedores os novos parâmetros a serem observados nas contratações pelo Poder Público. Tais consultas, de acordo com os levantamentos da pesquisa, visavam levar aos fornecedores do Governo do Estado de Minas Gerais, informações para que pudessem se adequar às novas exigências inseridas no edital de licitação, seguindo as mudanças ou adequações promovidas pelo Governo antes mesmo do início do processo licitatório.

Deve-se mencionar, o lançamento de uma cartilha de compras públicas sustentáveis 
pelo Governo do Estado de Minas Gerais, em evento ocorrido em dezembro de 2009, que reuniu todas as ações e iniciativas do governo estadual que introduziram a visão de sustentabilidade nas compras públicas realizadas pelo Governo. A cartilha lançada também com uma versão em língua inglesa, está disponível no sítio eletrônico de compras do Estado de Minas Gerais (www.compras.mg.gov.br), assim como sua forma impressa, em papel reciclado.

O Governo do Estado de Minas Gerais, ainda no âmbito da implantação das compras públicas sustentáveis, editou normas tratando do tema: o Decreto Estadual no 44.903 de 2008, estabeleceu procedimentos de controle ambiental a serem observados pela Administração Pública Estadual quando das contratações para execução de obras, serviços e aquisições que envolvam emprego de produtos e subprodutos de madeira, de origem nativa, com o claro objetivo e comprovar a legalidade de sua procedência; enquanto o Decreto Estadual no 45.229 de 2009, tratou de regulamentar medidas referentes ao combate às mudanças climáticas e gestão de emissões de gases de efeito estufa. Dentre as medidas propostas, destaca-se a obrigatoriedade pelo Poder Público de aquisição de veículos bicombustível, assim como a obrigatoriedade de abastecimento de veículos próprios ou em uso com etanol; e por sua vez, a Lei Estadual nº 18.719 de 2010, determina a utilização pelo Governo do Estado de Minas Gerais, na construção e recuperação das vias públicas, preferencialmente, de massa asfáltica produzida com borracha de "pneumáticos inservíveis" que, além de possuírem maior durabilidade, utilizam pneus usados.

Há ainda diversas outras normas editadas em Minas Gerais que, frisa-se, são de igual importância para a gestão pública ambiental, mas que não tratam de impor medidas concretas voltadas à implantação das compras públicas sustentáveis. Pode-se observar, também, a partir do levantamento documental, outras ações que o Governo do Estado de Minas Gerais vem adotando no exercício de sua atividade administrativa em que são observados critérios de sustentabilidade. Foi elaborado, por exemplo, um manual de "Obras Públicas Sustentáveis", no contexto do "Programa de Parceria para o Desenvolvimento de Minas Gerais II", assinado entre o Governo do Estado de Minas Gerais e o Banco Mundial, no qual as variáveis ecológica, cultural e social, assim como o período de vida útil do empreendimento em questão, devem ser consideradas.

\section{INSTITUCIONALIZAÇÃO DAS COMPRAS PÚBLICAS SUSTENTÁVEIS NO GOVERNO DE MINAS GERAIS}

Segundo Meyer e Rowan (1977), os ambientes institucionais caracterizam-se pela 
elaboração e difusão de regras e procedimentos, de modo a proporcionar às organizações, legitimidade e suporte contextual. Pela pesquisa documental e pelas entrevistas realizadas, percebe-se a importância de diversas forças institucionais neste processo de implantação das compras públicas sustentáveis no âmbito do Governo do Estado de Minas Gerais que formam o ambiente institucional.

O ICLEI é uma associação de governos locais, regionais e nacionais, fundada em 1990, com o objetivo de construir e compartilhar conhecimentos técnicos, assim como dar suporte a governos locais na promoção do desenvolvimento sustentável. Ao final de 2016, o ICLEI contava com a participação de aproximadamente 1500 governos locais, regionais e nacionais, espalhados em mais de 100 países. A premissa básica do ICLEI é de prestigiar as iniciativas locais, que podem culminar em um eficiente projeto local, regional ou nacional de desenvolvimento sustentável. As campanhas e programas ofertados pelo ICLEI envolvem agendas quanto a Ação Local; Cidades Sustentáveis; Proteção Climática; Biodiversidade; Cidades Resilientes; Mobilidade Sustentável; Comunidades Inclusivas; Instrumentos de Gestão, e Economia e Compras Públicas Sustentáveis.

Segundo um dos entrevistados, "a parceria com o ICLEI abriu os horizontes do governo para essa perspectiva das compras verdes (...), foi importantíssima para abrir a cabeça, para mostrar a importância do assunto, para mostrar que era viável fazer" (Entrevistado D). No mesmo sentido explica o Entrevistado F: "se não fosse o ICLEI bater em nossa porta para chamar a atenção desse assunto, oferecer uma doação, fazer essa cooperação com a FGV, a parte que cuida do cadastro, eu não sei se a gente teria começado, se a gente teria sido pioneiro" (Entrevistado F). A realização do Congresso Mundial do ICLEI em Belo Horizonte em 2012 dá uma dimensão da interação e busca de legitimidade institucional para as diversas ações governamentais nessa arena.

Outra importante força institucional foi a Fundação Getúlio Vargas - FGV, por meio de seu Centro de Estudos em Sustentabilidade - GVces. Durante o ano de 2007/2008, atendendo às demandas do estado de Minas Gerais, do estado de São Paulo e do município de São Paulo que surgiram durante a execução do projeto piloto "Fomentando as Compras Públicas Sustentáveis no Brasil", o GVces prestou consultoria técnica a estes entes federativos, consistente na identificação de critérios de sustentabilidade ambiental dos produtos, para fins de substituição daqueles tradicionais, constantes nos catálogos de compras do Governo. Ainda no âmbito da parceria celebrada, o GVces desenvolveu e aprimorou a tecnologia para identificação de produtos ambientalmente sustentáveis. Como resultado deste trabalho, o GVces disponibilizou um catálogo sustentável on-line, gratuito, com diversos 
itens, sua descrição, seus fornecedores e suas características ambientais. Um entrevistado ressalta: "qual a característica que vai fazer com que esse produto seja sustentável? É essa a parte mais difícil porque isto é muito técnico. Então, a Fundação Getúlio Vargas auxiliou a gente na definição de algumas características técnicas...” (Entrevistado A).

A partir da pesquisa realizada, verificou-se que a troca de experiências dos governos do estado de Minas Gerais com o do estado de São Paulo, e do município de São Paulo foi importante, pois todos eles enfrentavam problemas e dificuldades semelhantes na implantação das compras públicas sustentáveis, o que também foi observado por Oliveira e Santos (2015) em outros estados.

Também importante força institucional identificada no processo de implantação das compras públicas sustentáveis no Governo do Estado de Minas Gerais, atuando como financiador, foi o DEFRA - Department for Environment, Food and Rural Affairs, Ministério do Governo do Reino Unido, responsável pela elaboração de política pública e regulamentação nas áreas de biodiversidade, plantas, animais, alimentação, proteção ambiental, controle de poluição, entre outros naquele país. De acordo com um dos entrevistados, o fato do Governo do Estado de Minas Gerais, em um primeiro momento, não ter qualquer custo financeiro direto na implantação das compras sustentáveis, em decorrência do financiamento do DEFRA a fundo perdido, foi outro fator decisivo para adesão ao projeto apresentado pelo ICLEI: "então, esse é um projeto que a priori não gerava nenhum custo, então havia um incentivo, e o tema tem um apelo político” (Entrevistado D).

Assim, seguindo a perspectiva sugerida por Scott (2008), para a institucionalização de processo, a ação de forças institucionais (podendo ser grupos de interesse, parceiros estratégicos, entre outros), podem ser fundamentais na promoção de mudanças nas organizações, o que se viu confirmado na análise de dados a partir das entrevistas realizadas, com as forças institucionais como ICLEI, FGV, estado e município de São Paulo, configurando o ambiente institucional.

Barbieri et al. (2010, p.149) indicam que a institucionalização do conceito de desenvolvimento sustentável se dá "no âmbito das organizações intergovernamentais, como o PNUMA, PNUD, Banco Mundial, FMI, dos governos nacionais, e de ONGs com atuação internacional, como WWF e WBCSD”. Como resposta a estas pressões, surgem novos modelos tidos como mais adequados, ou inovações, como preconizam Tolber e Zulcker (2007), como é o caso das compras públicas sustentáveis.

As entrevistas realizadas demonstram claramente que a implantação das compras públicas sustentáveis no Governo do Estado de Minas Gerais, representa fonte de apoio e 
legitimidade no contexto em que se insere, nos moldes propostos por Meyer e Rowan (1977), facilitando o relacionamento com organismos de empréstimos internacionais, tais como Banco Mundial, Banco Interamericano de Desenvolvimento - BID, entre outros: "E nesse empréstimo também do Banco Mundial, na salvaguarda, que são aquelas questões ambientais que a gente tem que cumprir como contrapartida do empréstimo, (...) são mecanismos que a gente utiliza pra institucionalizar isto dentro do governo, porque se a gente não cumprir uma contrapartida eu tenho prejuízo no dinheiro que vai ser desembolsado pelo Banco Mundial, então a gente é obrigado a fazer. Então, é uma forma positiva da gente institucionalizar" (Entrevistado F).

Outro fato que pôde ser observado durante a pesquisa realizada, também na linha de regras e normas às quais as organizações devem se conformar, se pretendem receber apoio e obter legitimidade de outras organizações e da sociedade, foi a confecção pelo Governo do Estado de Minas Gerais de uma cartilha explicativa sobre o que são as compras públicas sustentáveis, e quais as ações empreendidas pelo governo estadual no sentido de sua implantação. Chama a atenção o fato da cartilha ter sido confeccionada em papel reciclado, além de disponível eletronicamente.

O mesmo se pode dizer da confecção do cartão de visita dos servidores em papel reciclado que, conforme um entrevistado, teve o intuito de passar uma imagem de incorporação de critérios de sustentabilidade nas ações diárias do Governo do Estado de Minas Gerais: "nós conseguimos que a Imprensa Oficial fizesse o mesmo preço do cartão branco, para o cartão reciclado. Então, isto por quê: qual a importância do cartão de visita? O cartão de visita ele... ele tem uma identidade..." (Entrevistado C). Ainda no campo da institucionalização, destaca-se a fala de um dos entrevistados quanto ao marketing institucional: "o texto que saiu a nível internacional, ... quando houve essa apresentação no Congresso Internacional do CLAD - Centro Latino-Americano de Administração para o Desenvolvimento, apresentou políticas de compras verdes tanto do estado de São Paulo como de Minas Gerais... a forma como a gente colocou a apresentação, ficou parecendo, para o CLAD, que Minas Gerais era muito mais avançada em compras sustentáveis do que São Paulo. Isso provocou ciúmes muito grandes" (Entrevistado A).

$\mathrm{Na}$ mesma linha de análise, a influência dos mecanismos de institucionalização descritos por DiMaggio e Powell (1991) relacionam-se tanto com a manutenção quanto com a mudança de práticas no contexto organizacional. A situação de mudança organizacional se configura pela incorporação de valores e práticas que tendem a provocar conflito de interesse, manifestado por resistências de seus membros, conforme atestam Tolbert e Zucker (2007). A 
partir dos levantamentos realizados, pode-se verificar algumas barreiras neste processo de implantação das compras públicas sustentáveis no Governo do Estado de Minas Gerais, consideradas inerentes ao próprio processo de mudança: “qual que é o grande desafio, na minha opinião, na administração pública hoje: é a questão da mudança. Houve um processo de resistência para as compras verdes? Sim, houve. Foi porque eram compras verdes? Não. Em todos os novos projetos houve resistências" (Entrevistado D).

Uma das barreiras mencionadas pelos entrevistados neste processo de implantação das compras públicas sustentáveis no âmbito do Governo do Estado de Minas Gerais diz respeito ao uso do papel A4 reciclado que, além de ser tido como "feio" pelos servidores, era de difícil leitura em decorrência do contraste da letra com o papel reciclado: “às vezes... se num órgão, se do dia para a noite, você exige, por exemplo, o papel reciclado: Ah! Mas porquê se a vida inteira foi assim? Esse papel é feio! Esse papel não está valorizando o meu trabalho!" (Entrevistado C).

Outra barreira que se pode perceber pelas entrevistas foi o marco legal que rege as compras públicas no Brasil: “O que acontece: a Lei 8.666 ela, em regra geral, ela pede o menor preço... existe realmente uma dificuldade legal porque a lei, ela é feita dentro de uma realidade, (...) em relação a isto, eu sei que tanto o ICLEI e como vários órgãos ambientais, existe uma mobilização dentro do congresso para a abertura deste conceito e alterações de regulamentações" (Entrevistado C).

As resistências apresentadas no processo de implantação das compras públicas sustentáveis no Governo do Estado de Minas Gerais vêm sendo superadas, mormente considerando-se que, de acordo com Dimaggio e Powell (1991), as organizações tornam-se cada vez mais semelhantes a fim de adequarem ao ambiente em que se inserem. Para tal, lançam mão de práticas isomórficas de natureza coercitiva, mimética e normativa. Verificouse na pesquisa que uma das formas encontradas pelo Governo de Minas Gerais para transpor as resistências ocorridas no processo de implantação das compras públicas sustentáveis foi por meio de práticas isomórficas de natureza coercitiva. Pelo isomorfismo coercitivo, as estruturas organizacionais modificam devido a pressões formais ou mesmo informais exercidas sobre a organização por outras das quais ela dependa ou, ainda, pelas experiências culturais da sociedade em que as organizações atuam. Um dos instrumentos de gestão utilizados que caracteriza o isomorfismo coercitivo é o "Acordo de Resultados", instrumento de pactuação de resultados que estabelece, por meio de indicadores e metas, quais compromissos deveriam ser alcançados pelos órgãos e entidades do Executivo mineiro, sendo monitorados pela Secretaria de Estado de Planejamento e Gestão - SEPLAG. No caso de 
cumprimento das metas pactuadas, os orçamentos eram mantidos para os órgãos e entidades, enquanto os servidores recebiam recompensas monetárias e não monetárias.

A aquisição do papel A4 reciclado pelos órgãos e entidades do Governo do Estado de Minas Gerais, fonte de resistência por parte dos servidores, passou a constar como uma das metas a ser cumprida no Acordo de Resultados, pressionando, assim, sua aquisição, sob pena de não se atingir as metas acordadas. De acordo com um dos entrevistados: "Depois, veio a questão do papel, então o Estado colocou uma meta para todos os órgãos de comprar, só usar papel reciclável, tanto que hoje você olha assim, já é prática. (...) Foi uma implementação lá de 2006, 2007 que hoje permanece” (Entrevistado E).

O programa “AmbientAÇÃO”, criado em 2003, um programa de comunicação e educação socioambiental que tem como objetivo promover a sensibilização para a mudança de comportamento e a internalização de atitudes ecologicamente corretas no cotidiano dos servidores públicos de Minas Gerais, na parte que trata da coleta seletiva do lixo, também foi inserido no "Acordo de Resultados" dos órgãos em 2007. De fato, durante a realização da pesquisa, nos órgãos públicos do estado de Minas Gerais, observou-se a existência da coleta seletiva do lixo, processo que se manteve ao longo do tempo, abrangendo em 2016 um total de 50 prédios públicos.

É importante esclarecer que as compras públicas em geral realizadas pelo estado de Minas Gerais são todas geridas pela Secretaria de Estado de Planejamento e Gestão, a quem cabe formular e alimentar o catálogo de compras do Estado - CATMAS, por meio do Sistema Integrado de Materiais e Serviços - SIAD. Neste ponto, a SEPLAG tem como controlar os produtos adquiridos por toda a Administração Pública do Estado de Minas Gerais, uma vez que só pode ser adquirido produto que conste no catálogo de compras. Deste modo, a inserção de determinado produto no catálogo de compras do Governo segue as linhas traçadas no projeto de Gestão Estratégica de Suprimentos, no qual, como citado anteriormente, consideram-se os critérios de sustentabilidade.

Segundo um dos entrevistados, a confecção do catálogo para aquisição de produtos e serviços, "auxiliou bastante a disseminação da compra desses produtos nos órgãos. $O$ catálogo de materiais é controlado pela SEPLAG, então eles adquirem o que está catalogado no catálogo e aí a gente é que define o item que sai e o item que entra" (Entrevistado B).

Percebe-se, também, outra prática de natureza coercitiva que contribui para a implantação das compras sustentáveis pelo Governo do Estado de Minas Gerais. Aqui, importante ressaltar que Meyer e Rowan (1977) afirmam que o êxito organizacional depende de outros fatores que não somente a coordenação e o controle eficiente das atividades 
produtivas. Ao desenhar uma estrutura formal que se adequa ao ambiente institucional, uma organização demonstra que atua com bases em valores coletivamente aceitos, de maneira adequada. A fala dos entrevistados reforça essa visão, como se pode depreender do relato a seguir: "Então, na verdade, quando a gente implementou esse processo, os compradores do Estado não tinham autonomia de comprar ou não isso, eles tinham um decreto que os obrigava a aderir a esse modelo, e esse modelo é um modelo hoje, que eu apresento, que o governo de Minas apresenta, dizendo o que é compras verdes no governo de Minas Gerais" (Entrevistado D).

Conforme verificado na pesquisa, no âmbito do Governo do Estado de Minas Gerais, o processo de implantação das compras públicas sustentáveis ficou a cargo da SEPLAG, tida como uma secretaria central, focada principalmente na gestão, com "ascendência" sobre as demais secretarias e órgãos do Governo do Estado de Minas Gerais. Neste sentido, os entrevistados apontaram como um dos motivos de Minas Gerais avançar mais, quando comparado ao município de São Paulo e ao estado de São Paulo, outros dois pioneiros entes federativos na execução do projeto "Fomentando as compras públicas sustentáveis no Brasill", pois no caso paulista, as ações estavam sob a égide das pastas de Meio Ambiente: "Isto aqui foi facilitado porque, por exemplo, no governo de São Paulo, eles tinham uma dificuldade que quem estava participando deste projeto de compras sustentáveis era o [a Secretaria de] Meio Ambiente, (...), só que eles não tinham força para poder implementar no resto do governo, como não era a área central, eles conseguiam implementar na Secretaria de Meio Ambiente e para extrapolar isso daí, eles precisavam de uma normatização do governo. Aqui na SEPLAG a gente consegue fazer isto..." (Entrevistado B).

Um outro mecanismo isomórfico, descrito por DiMaggio e Powell (1991), é o normativo, pelo qual há um esforço coletivo para definir condições e métodos de trabalho. Como resultado da profissionalização de administradores, passa-se a divulgar normas e técnicas de gestão convergentes. No caso da presente pesquisa, pelas entrevistas realizadas, verifica-se que foi realizado um trabalho com os servidores do Governo do Estado de Minas Gerais responsáveis pelas compras, no sentido de capacitá-los para as mudanças decorrentes da implantação das compras públicas sustentáveis: “a gente teve a preocupação de vir o ICLEI, a Fundação Getúlio Vargas, nós reunimos todos os compradores, ordenadores do Estado no sentido de começar essa conscientização, essa importância: Olha! O Estado... e está acontecendo isto no mundo e isto tem um impacto no cidadão. O cidadão exige isto do Estado e o Estado está colocando para vocês que ele vai iniciar uma política de sustentabilidade e foi mostrado esse panorama para os gestores chefes. Então, foram, 
geralmente, os chefes de gabinetes, o SPGF que é responsável pela compra, eles foram convocados pelos ordenadores de despesas para essa capacitação” (Entrevistado C).

No entanto, pelas entrevistas realizadas, não se pode afirmar que as práticas de isomorfismo normativo, tal como descritas por DiMaggio e Powell (1991), estavam completamente disseminadas na Administração Pública do Estado de Minas Gerais. Isto porque, apesar da capacitação dos servidores estaduais na etapa inicial do processo de implantação das compras públicas sustentáveis pelo Governo de Minas Gerais, não se constatou a continuidade da referida prática de capacitação ao longo do tempo. Quando questionados se o corpo técnico estaria apto para realização das compras públicas sustentáveis após a realização de cursos de capacitação, a resposta de maneira geral foi negativa: "Eu acho que não, precisa avançar muito" (Entrevistado D). Ainda que em levantamentos posteriores os procedimentos básicos continuassem a ser praticados, fatores como as limitações orçamentárias e financeiras do estado comprometiam a disseminação da prática, conforme previstos por Silveira et al. (2012).

Ainda, um terceiro mecanismo de prática isomórfica, descrito por DiMaggio e Powell (1991), é aquela de natureza mimética, pelo qual as instituições, diante da incerteza decorrente de tecnologia não compreendida, incerteza simbólica, ou metas ambíguas, tomam como modelo, organizações que percebem ser mais legítimas ou bem-sucedidas, de modo a economizar esforço e tempo. No caso do estado de Minas Gerais, com o auxílio do ICLEI, utilizou-se da experiência bem-sucedida na implantação de compras públicas sustentáveis em localidades atendidas pelo ICLEI-Europa, tais como as cidades de Gotenborg, na Suécia; Kaarst, na Alemanha, entre outros, de forma a colaborar com o Governo do Estado de Minas Gerais em seu processo de implantação.

Neste ponto, pela pesquisa realizada, pode-se observar que o governo do estado de Minas Gerais, juntamente com o do estado de São Paulo e o do município de São Paulo, pioneiros neste processo de implantação de compras públicas sustentáveis, passaram a “exportar" o modelo aqui implantado para outros entes federativos. O seguinte relato denota essa perspectiva: "Hoje o ICLEI vai para parceria com outros governos, por exemplo, e acaba levando Minas e fica aquela coisa assim: como que isto aconteceu em Minas Gerais? Porque a parte do como fazer é um dificultador muito grande dos governos, eles têm a vontade, eles querem implantar as compras sustentáveis, mas como fazer, esta é a parte difícil: Olha, gente! Minas conseguiu, então não é impossível. Como que vocês fizeram? E levam o caso aqui de Minas pra outros estados... ok?" (Entrevistado B). Os estudos de Oliveira e Santos (2015) indicam essa expansão, ainda que tímida. 
Na tipologia analítica, descrita por Scott (2008), verifica-se a predominância do pilar regulador, tais como a inserção pela SEPLAG de critérios ambientais no Acordo de Resultado com os órgãos, a centralização da confecção do catálogo de compras estaduais, também pela SEPLAG, a edição de decretos determinando a observância da origem da madeira, a edição de portarias para regular o consumo de energia e água nos órgãos, entre outros. Todavia, elementos observados na pesquisa indicam a ocorrência da base de sustentação normativa da instituição, como a implantação da coleta seletiva do lixo que, em virtude de sua execução repetitiva, tem-se tornado um valor individual de alguns servidores: "é interessante você vê essa consciência que vai criando e eu tenho aqui o depoimento de algumas pessoas, que acaba que você leva isso para dentro da sua casa. Então, eu acho que tem um papel que é educativo e aí você vai passando pro seus filhos, você tem que acreditar que você é um indutor disso e que são pequenas atitudes que vão transformar" (Entrevistado F). Estudos como os de Couto e Coelho (2015) confirmam tal premissa.

Neste processo de implantação das compras públicas sustentáveis no âmbito do Governo do Estado de Minas Gerais observa-se, ainda, alguns traços do pilar cognitivo descrito por Scott (2008), para quem a atenção é direcionada para os aspectos simbólicos das ações, resultantes das interpretações e representações dos indivíduos em relação ao ambiente em que se inserem, ainda que estes seja mais lentos para serem incorporados e as ações de treinamento e capacitação que possuem grande valia nesse contexto não tenham sido continuados.

Outros exemplos também podem ser mencionados, como no caso da proposição de não utilização de copo plástico. De acordo com a fala de um dos entrevistados, houve resistência dos servidores em substituir o uso do copo plástico descartável por uma caneca, fornecida pela própria Administração Pública do Estado de Minas Gerais. Diante de uma série de reclamações, a opção ao uso do copo plástico descartável passou a ser facultativa e não obrigatória. Todavia, como forma de "constranger" aqueles que optaram pelo uso de copo plástico descartável, é divulgado mensalmente os órgãos que aderiram ao uso da caneca, em detrimento do uso do copo plástico, gerando, assim, uma pressão da organização nos órgãos para a adesão ao uso da caneca, tida como ambientalmente correta. Esse episódio retoma a dinâmica de resistência no interior das organizações na institucionalização nos termos de Tolbert e Zucker (2007).

Uma das questões expressas pelos entrevistados, que muito contribuiria para a institucionalização das compras públicas sustentáveis no âmbito do Governo do Estado de Minas Gerais, é a edição de um decreto, dispondo de forma clara a opção do Governo para 
aquisição de produtos e serviços sustentáveis: "Então, um dos desafios vai ser institucionalizar isso, inclusive através de normatização, não tem uma norma ainda no governo de Minas Gerais para compras sustentáveis. Isto ia ser feito ano passado e a gente acabou adiando, este é um dos desafios" (Entrevistado B). Chama a atenção o fato de que, não obstante a legislação federal já permitir as compras públicas sustentáveis, os entrevistados ainda assim frisaram a necessidade da edição de uma norma específica e clara neste sentido, de modo a "acelerar" o processo de institucionalização no âmbito Estadual. Tal fato é corroborado pela tese defendida por Machado-da-Silva e outros (2003) que destacam o mecanismo institucional coercitivo como instrumento mais eficaz, seja na manutenção, seja na transformação social, no âmbito da sociedade brasileira, de forte tradição patrimonialista: "Em uma sociedade como a brasileira, fortemente influenciada por padrões estrangeiros, torna-se mais fácil adotar uma estrutura formal por decreto ou lei do que institucionalizar o correspondente comportamento social” (MACHADO-DA-SILVA et al., 2003, p. 188).

De fato, na pesquisa realizada, conforme acima exposto, observou-se a prevalência de instrumentos coercitivos no processo de implantação das compras públicas sustentáveis no âmbito do Governo do Estado de Minas Gerais. Pode-se observar, ainda, que todos os entrevistados afirmaram que, dado o poder de compras do Governo do Estado de Minas Gerais, a implantação das compras públicas sustentáveis teria o condão de alterar a cadeia produtiva, de modo a se formar um mercado de produtos sustentáveis, inclusive com alteração no preço final de ditos produtos: "Quando a gente começou a comprar o papel reciclado, começou com uma meta muito tímida porque ele era mais caro, hoje ele tá mais barato do que o papel branco porque a gente começa a consumir e o preço começar a cair. Eu não tenho dúvida que o poder de compra do governo influencia positivamente nisso..." (Entrevistado F). Para uma dimensão desse poder, o volume de compras totais de produtos e serviços pelo Governo do Estado de Minas Gerais foi em média de 7 bilhões e meio de reais por ano no período de 2011 e 2015.

As falas dos entrevistados mostram a influência do estado de Minas Gerais no fortalecimento da dimensão da sustentabilidade, uma vez que pode influenciar o fornecimento de produtos e serviços pelo mercado, o que poderá, no ambiente institucional estudado, formar um conjunto de preceitos por meio de regulamentos, decretos, e legislação, que serão legitimados ao longo do tempo, tonando-se cada vez mais homogêneos nos termos preconizados por Meyer e Rowan (1977), e tomados pelo pilar cognitivo de Scott (2008) incorporados nas práticas organizacionais e dos indivíduos como sugerem os estudos de Couto e Coelho (2015). Porém, ainda não se encontram sedimentados nos termos de Tolbert e 
Zucker (2007, p.203).

Tal fato levanta indícios de uma consolidação futura em torno das compras públicas sustentáveis, de modo que possa se difundir por outros entes públicos, pela iniciativa privada e a sociedade em geral. Nesta seara, os entrevistados afirmaram que, não obstante os avanços já alcançados pelo Governo do Estado de Minas Gerais, na implantação das compras públicas sustentáveis, ainda há um longo caminho a ser percorrido, de modo a atingir sua institucionalização. As dificuldades econômicas e orçamentárias a partir de 2014, já vislumbradas por Silveira et al. (2012), reforçaram a lentidão na institucionalização das compras verdes no âmbito governamental.

\section{CONSIDERAÇÕES FINAIS}

Dentre os diversos instrumentos à disposição do Poder Público para a execução da gestão ambiental, pode-se citar uma modalidade que vem ganhando importância em tempos recentes: as compras públicas sustentáveis; vez que tal instrumento, ao mesmo tempo que diminui os impactos ambientais negativos decorrentes do desempenho de suas atividades administrativas diuturnas, estimula, ainda, a criação de um novo mercado de produtos e serviços sustentáveis.

Pelos dados coletados na pesquisa, percebeu-se que o Governo do Estado de Minas Gerais foi um dos pioneiros na implantação de uma política pública voltada especificamente para a difusão de compras públicas sustentáveis por parte do Estado. Muito do que foi alcançado pode ser atribuído à atuação de forças institucionais (grupos de interesses e parceiros estratégicos) que, segundo a perspectiva sugerida por Scott (2008), podem se fazer fundamentais na promoção de mudanças. A partir dos dados coletados com o presente estudo de caso, confirmou-se a importância dessas forças institucionais no campo organizacional analisado, com destaque para como o ICLEI e o projeto "Fomentando as Compras Públicas Sustentáveis no Brasil".

Ao se analisar o processo de institucionalização das compras públicas sustentáveis no âmbito do Governo do Estado de Minas Gerais vê-se sua conformação ao ambiente institucional geral, de modo a se adequar a esta "onda" do desenvolvimento sustentável; aumentando sua legitimidade no ambiente institucional, facilitando suas trocas e relacionamentos com organismos de empréstimos internacionais, tais como o Banco Mundial dentre outros.

No caso do Governo do Estado de Minas Gerais, verifica-se que, para a implantação 
das compras públicas sustentáveis utilizou-se, primordialmente, de mecanismos isomórficos coercitivos, tais como o Acordo de Resultados, a execução do projeto Gestão Estratégica de Suprimentos - GES, e a edição de decretos e portarias. Quanto aos pilares de sustentação das organizações descritos por Scott (2008), percebe-se, no caso analisado, a predominância do pilar regulativo, que tem como base de legitimação as normas legalmente postas. Novamente, vale frisar que foram observados, ainda que de forma muito incipiente, características de sustentação do pilar normativo e indícios do pilar cognitivo. Estas conclusões coincidem com as análises desenvolvidas por Machado-da-Silva e outros (2003), que afirmam que a mudança organizacional mais eficaz, em sociedades como a brasileira, de forte tradição patrimonialista, se dá por meio de práticas isomórficas coercitivas, haja vista ser mais fácil adotar uma estrutura de organização por lei ou decreto, do que institucionalizar o correspondente comportamento social. Para tal, cabe ressaltar o fato do processo ter sido conduzido pela SEPLAG, considerada uma secretaria central, focada principalmente na gestão, com "ascendência" sobre os demais órgãos e entidades do estado de Minas Gerais, o que lhe conferiu poderes para "impor" as compras públicas sustentáveis para toda a Administração Pública estadual.

A partir dos dados da pesquisa, observa-se também que a inserção de critérios de sustentabilidade nas aquisições de produtos e serviços pelo Governo do Estado de Minas Gerais pode conduzir a uma alteração na cadeia produtiva do setor empresarial, em face do poder de compra deste ente federativo que foi da ordem de 7,5 bilhões de reais entre 2011 e 2015. Por meio dessa capacidade de influência do Governo do Estado, podem aparecer novos conjuntos de preceitos por meio de regulamentos, decretos, e legislação que serão legitimados ao longo do tempo, tornando as práticas de sustentabilidade vez mais homogêneas nos termos preconizados por Meyer e Rowan (1977), e convergindo futuramente para novas dinâmicas no campo organizacional em torno delas.

Os dados apontam ainda que, depois do grande esforço inicial para a implantação das compras públicas sustentáveis pelo Governo do Estado de Minas Gerais, verifica-se uma lentidão nas ações empreendidas neste sentido, a começar pela parceria celebrada entre o Governo do Estado de Minas Gerais e o ICLEI, mantida apenas em caráter formal, sem que haja troca de informações ou auxílio. Além disso, não se tem mais notícias de realização de cursos de capacitação sobre compras públicas sustentáveis para os servidores responsáveis pelas compras governamentais, o que pode dificultar a assimilação e internalização de valores por estes servidores e aqueles que venham a assumir tais atividades. As dificuldades orçamentárias e econômicas a partir de 2014 reforçam esse quadro. Estas questões evidenciam 
que o processo de compras públicas sustentáveis ainda não se encontra institucionalizado no Governo do Estado de Minas Gerais.

Por fim, como contribuição no campo da gestão, o artigo indica que práticas voltadas para ampliar ações sustentadas por meio de compras sustentáveis, ainda não estão disseminadas na área pública. Assim, cumpre aqui esclarecer a necessidade de investigações que aprofundem a análise destas questões, uma vez que a presente pesquisa, não almeja esgotar o instigante tema das compras públicas sustentáveis. Nesta linha, seria interessante um trabalho de pesquisa que investigasse a maneira como os órgãos e entidades da Administração Pública, bem como em organizações privadas, estão abordando essas questões, assim como quais são suas ações no sentido de realização de compras públicas sustentáveis.

\section{REFERÊNCIAS}

ABRAMOVAY, R. Desenvolvimento sustentável: qual a estratégia para o Brasil? Novos Estudos CEBRAP, São Paulo, n. 87, p. 97-113, jul. 2010.

ALPERSTEDT, G. D.; QUINTELLA, R. H.; SOUZA, L. R. Estratégias de gestão ambiental e seus fatores determinantes: uma análise institucional. Revista de Administração de Empresas, São Paulo, v. 50, n. 2, p. 170-186, jun. 2010.

ANDRADE, J. C. S.; COSTA, P. Mudança climática, Protocolo de Kyoto e mercado de crédito de carbono. Organizações \& Sociedade, Salvador, v. 15, n. 45, p. 29-46, abr./jun. 2008.

BALDIN, N.; MUNHOZ, E. Snowball (Bola de Neve): uma técnica metodológica para pesquisa em educação ambiental comunitária. In: CONGRESSO NACIONAL DE EDUCAÇÃO, X, 2011, Curitiba. Anais... Curitiba: PUC-PR, 2011. v.1, p.329-341.

BARBIERI, J. C. et al. Inovação e sustentabilidade: novos modelos e proposições. Revista de Administração de Empresas, São Paulo, v. 50, n. 2, p.146-154, abr./jun. 2010.

BARBIERI, J. C. Desenvolvimento e meio ambiente. Petrópolis: Vozes, 2009.

BARBIERI, J. C. Gestão ambiental empresarial. São Paulo: Saraiva, 2004.

BIDERMAN, R. et al. (Org). Guia de compras públicas sustentáveis. Rio de Janeiro:

Editora FGV, 2008.

BLIACHERIS, M. W. Licitações sustentáveis: política pública. In: SANTOS, M.; BARKI, T. (Coord.). Licitações e contratações públicas sustentáveis. Belo Horizonte: Fórum, 2011. p. 137-152. 
BRASIL. Ministério do Planejamento. Compras Públicas Sustentáveis. Brasília: Ministério do Planejamento, 2015. Disponível em:

http://cpsustentaveis.planejamento.gov.br/noticias/workshop-no-planejamento-debatecompras-publicas-sustentaveis. Acesso em: 3 mar. 2016.

BRULON, V.; VIEIRA, M. M. F.; DARBILLY, L. Choque de gestão ou choque de racionalidades? o desempenho da administração pública em questão. REAd. Revista Eletrônica de Administração, v. 19, n. 1, p. 1-34, abr. 2013.

COLBARI, A. A análise de conteúdo e a pesquisa empírica qualitativa. IN: SOUZA, E. M.

(Org.). Metodologias e analíticas qualitativas em pesquisa organizacional: uma abordagem teórico-conceitual. Vitória: EDUFES, 2014. p. 241-272.

COSTA, D.; TEODÓSIO, A. Desenvolvimento sustentável, consumo e cidadania. Revista de Administração Mackenzie, São Paulo, v. 12, n. 3, p. 114-145, jun. 2011.

COUTO, H. L. G.; COELHO, C. Fatores críticos no comportamento do gestor público responsável por compras sustentáveis: diferenças entre consumo individual e organizacional.

Revista de Administração Pública, Rio de Janeiro, v. 49, n. 2, p. 519-543, mar./abr. 2015.

CRESWELL, J. W. Projeto de pesquisa. Porto Alegre: Artmed, 2010.

DIMAGGIO, P. J.; POWELL, W. W. The iron cage revisited: institutional isomorphism and collective rationality in organizational fields. In: POWELL, W. W.; DIMAGGIO, P. J. (Ed.). The new institutionalism in organizational analysis. Chicago: University of Chicago Press, 1991. p. 63-82.

ENSSLIN, S. R. et al. Compras governamentais sob a ótica da avaliação de desempenho: um mapeamento do tema conforme as delimitações postas pelos pesquisadores. Gestão \& Regionalidade, São Caetano do Sul, v. 30, n. 90, p. 32-49, set./dez. 2014. GONÇALVES-DIAS, S; TEODOSIO, A.; BARBIERI, J. C. Desafios e perspectivas da sustentabilidade. In: ENCONTRO NACIONAL SOBRE GESTÃO EMPRESARIAL E MEIO AMBIENTE, XI, 2007, Curitiba. Anais... Curitiba: UNICENP, 2007. v. 1, p. 1-11. GROB, S.; BENN, S. Conceptualising the adoption of sustainable procurement: an institutional theory perspective. Australasian Journal of Environmental Management, v. 21, n. 1, p. 11-21, Feb. 2014.

LIMA, L. O Tribunal de Contas da União e o controle externo da gestão ambiental. 2009. 365f. Tese (Doutorado) - Programa de Pós-Graduação Interdisciplinar de Engenharia Ambiental, COPPE, Universidade Federal do Rio de Janeiro, Rio de Janeiro, 2009. MACHADO-DA-SILVA, C.; FONSECA, V. Homogeneização e diversidade organizacional: uma visão integrativa. In: ENCONTRO ANUAL DA ASSOCIAÇÃO NACIONAL DE PÓS- 
GRADUAÇÃO E PESQUISA EM ADMINISTRAÇÃO, 17, 1993, Salvador. Anais... Salvador: ANPAD, 1993. v. 9, p. 147-159.

MACHADO-DA-SILVA, C. et al. Institucionalização da mudança na sociedade brasileira: o papel do formalismo. In: VIEIRA, M. M. F.; CARVALHO, C. A. (Org.). Organizaçõoes, instituições e poder no Brasil. Rio de Janeiro: Editora FGV, 2003. p. 179-202 MAPURUNGA, P. V. R.; LIMA, B. C. C.; HOLANDA, A. P. Disclosure social e isomorfismo nas empresas listadas no Índice de Sustentabilidade Empresarial. Revista de Administração da UFSM, Santa Maria, v. 8, n. 2, p. 267-281, abr./jun. 2015.

MAY, T. Pesquisa social. Porto Alegre: Artmed, 2004.

MENEGUZZI, R. Conceito de licitação sustentável. In: SANTOS, M.; BARKI, T. (Coord.). Licitações e contratações públicas sustentáveis. Belo Horizonte: Fórum, 2011. p. 19-36. MEYER, J. W.; ROWAN, B. Institutionalized organizations: formal structure as myth and ceremony. American Journal of Sociology, Chicago, v. 83, n. 2, p. 340-363, 1977. MINAYO, M. C. S. O desafio do conhecimento. São Paulo: Hucitec, 1996. OECD. Greener public purchasing: issues and practical solutions. Paris: OECD Publications, 2000.

OLIVEIRA, B. C.; SANTOS, L. M. Compras públicas como política para o desenvolvimento sustentável. Revista de Administração Pública, Rio de Janeiro, v. 49, n. 1, p. 189-206, fev. 2015.

PEREIRA, F. A. M. A evolução da teoria institucional nos estudos organizacionais: um campo de pesquisa a ser explorado. Revista Organizações em Contexto, São Bernardo do Campo, v. 8, n. 16, p. 275-295, jul./dez. 2012.

QUEIROZ, R. G. M.; CKAGNAZAROFF, I. B. Inovação no setor público: uma análise do choque de gestão (2003-10) sob a ótica dos servidores e dos preceitos teóricos relacionados à inovação no setor público. Revista de Administração Pública, Rio de Janeiro, v. 44, n. 3, p. 679-705, jun. 2010.

RIBEIRO, M. Origens mineiras do desenvolvimento sustentável no Brasil: ideias e práticas. In: PÁDUA, J. (Org.). Desenvolvimento, justiça e meio ambiente. Belo Horizonte: Editora UFMG, 2009. p. 124-175.

SCOTT, W. R. Institutions and organizations: ideas and interests. London: Sage, 2008.

SELZNICK, P. Institutionalism “Old” and "New”. Administrative Science Quarterly, Ann Arbor, v. 41, p. 270-277, jun. 1996.

SILVA JÚNIOR, A. et al. Oportunidades para compras verdes no setor de suprimentos da Petróleo Brasileiro S.A. Revista Contextus, Fortaleza, v. 7, n. 1, p. 69-80, jan./jun. 2009. 
SILVA, R. C.; BARKI, T. V. P. Compras públicas compartilhadas: a prática das licitações sustentáveis. Revista do Serviço Público, Brasília, v. 63, n. 2, p. 157-175, abr./jun. 2012. SILVEIRA, M. C.; FONSECA, G. P. S.; OLIVEIRA, K. P. Os limites fiscais e orçamentários da reforma gerencial nos estados: o exemplo de Minas Gerais. Contabilidade Vista \& Revista, Belo Horizonte, v. 23, n. 1, p. 127-163, jan./mar. 2012.

TOLBERT, P.; ZUCKER, L. A institucionalização da teoria institucional. In: CLEGG, S. R.; HARDY, C.; NORD, W. (Org.). Handbook de estudos organizacionais. São Paulo: Atlas, 2007. p. 194-217.

YIN, R. K. Estudo de caso: planejamento e métodos. Porto Alegre: Bookman, 2010. 